\title{
The Impact of Traditional Approach to Chinese Literacy Education on English Language Teaching
}

\author{
Xia $\mathrm{Yu}^{*}$ \\ School of Foreign Languages \\ Southwest University of Political Science and Law \\ Chongqing, China
}

\begin{abstract}
Text memorization is a widely used yet underexplored language practice in foreign language education in China and other Confucian heritage countries. The present study addresses the need for a comprehensive and in-depth understanding of the perceptions of Chinese teachers regarding the use of text memorization in their teaching practices. This study based its methodology on semi-structured interviews and the data was collected from a group of Chinese teachers $(\mathrm{N}=20)$ affiliated with 16 schools or universities at three different educational levels, i.e. junior high, senior high and college, which constitute the major part of foreign language education in China. The qualitative data analyses revealed that most teachers insist on the use of text memorization as they do not see any negative impact of this practice on understanding, creativity and motivation. The results show that teachers' perception of this traditional approach to Chinese literacy education appears to be over-positive, and Chinese teachers are advised to employ it sensitively, sensibly and inquiringly.
\end{abstract}

Keywords-text memorization; understanding; creativity; motivation; teaching device

\section{INTRODUCTION}

Although Confucian authoritarian education has long fallen into disfavour in modern China and the status of text memorization as a learning method has thus been challenged (Ting, 2004), the practice of memorising textual materials among Chinese learners seems to be dying hard. Today text memorization is still widely practiced in schools throughout China (Jin \& Cortazzi, 2002; Ting, 2004; Yu, 2014). Students may spend hours memorising texts and some teachers require individual students to recite these texts in class or in the teachers' offices (Jin \& Cortazzi, 2002). Learning texts by heart seems to be gaining attention from language educators and researchers as an increasing number of cases of successful English learners are reported claiming to have intensively employed this practice as a learning strategy (see, e.g., Gao, 2007; Huang \& Qi, 2005; Ting, 2004, 2007; Wen, 1996). One example in point is that a widely used textbook series for nonEnglish majors in university, College English - Integrated Course (Li, Zhang, \& Wang, 2001), for the first time, to the best of my knowledge, set in each unit a regular assignment of learning by heart several (usually 3 to 4 ) paragraphs in the text. This may epitomise an official recognition of the value of this traditional way of learning. Why has Chinese educational authority never dispensed with textual memorisation even up to the new century when economic reforms and prosperity have profoundly changed almost every aspect of Chinese society including its value system? Why have Chinese teachers persisted in using this traditional way of learning rooted in Chinese literacy education which is apparently not in keeping with modern views on methodology? This is the overall motivation underpinning this investigation.

\section{LITERATURE REVIEW}

The past decades have seen increasing number of empirical studies on learning texts by heart. Ting (2004) investigated the beliefs and strategies concerning the learning and using of language chunks through text memorization by examining journal entries and interview reports produced by a group of English majors in a prestigious university in China. The author attempted to tap into - among other things - the following two issues: students' opinions as to the effectiveness of the method of learning text by heart and their comparison of learning text by heart with other methods. It was found that the participants viewed the method of textual memorization as effective in helping them to improve both their speech and writing despite the hardship they have experienced.

Gao (2007) conducted a longitudinal ethnographic inquiry into mainland Chinese undergraduates' shifting strategic engagement in acquiring English competence on the Chinese mainland and Hongkong. Twenty-two mainland Chinese students were interviewed about their language learning experiences on the Chinese mainland, immediately after their arrival in Hongkong and fifteen of them were interviewed for the second time about their language learning experiences in Hongkong. The participants were a group of relatively successful or 'elite' Chinese learners from a middle-class family background. It was reported that many participants in this study found the memorization of textual materials (either in the form of English essays, speeches or song lyrics) helpful with their English learning.

$\mathrm{Yu}$ (2014) reports on findings from semi-structured interviews concentrating on the perceptions of textual memorization as a way of learning from the learners' perspective. The data was collected from a group of Chinese learners and teachers $(\mathrm{N}=62)$ affiliated with 15 schools and universities at three different educational levels. Qualitative analyses of the data revealed that the practice was perceived to be beneficial not only because it assists learning in a number of 
ways but because it affords the learners psychological satisfaction built on their sense of achievement and confidence.

Although there are a number of studies on learners' perceptions of textual memorization as a learning strategy, there has been a lack of empirical study of how text memorization is perceived from the perspective of teaching. The present study therefore addresses this gap in literature by accessing the voice of a group of Chinese teachers from three educational levels. The study sets out to answer the following quantitative research questions:

1) What are teachers' overall attitudes towards the practice of text memorization?

2) What are teachers' perceptions of the impact of text memorization on understanding, creativity and motivation?

\section{METHODOLOGICAL FRAMEWORK}

\section{A. Participants}

The participants in the teacher interview survey were 20 language teachers from three educational levels, i.e. junior high school, senior high school and college/university. They ranged from 24 to 65 years in age with the majority in their twenties and thirties; the average age was 35. Their experience in teaching English varied from 1 to 43 years, with an average of 11 years. More detailed background information on the participants gathered by questionnaire is presented in Table I.

TABLE I.

BACKGROUND INFORMATION OF INTERVIEW PARTICIPANTS

$\begin{array}{lllll}\text { Participants }^{2} & \begin{array}{l}\text { Educational } \\ \text { level(Grades) }\end{array} & \text { Age } & \text { Sex } \quad \text { Teaching experience and qualification }\end{array}$

\begin{tabular}{ll}
\hline Years of & Type of school \\
teaching
\end{tabular}

\begin{tabular}{lllllll}
\hline Yuli & Junior High-3 & 35 & F & 14 & Public & two-year college \\
& & & & & & (N/A) \\
Jiajie & Junior High-1 & 29 & F & 4 & Public & BA \\
Wenna & Junior High-1 & 26 & F & 4 & Public & BA \\
Liuxia & Junior High-1,2 & 24 & F & 3 & Private & BA \\
Yaoqing & Junior High-2 & 27 & F & 5 & Public & BA \\
Liangying & Junior High-3 & 38 & F & 15 & Public & BA \\
Tangming & Junior High-2 & 36 & F & 13 & Public & BA \\
Wangting & Senior High-1 & 33 & F & 11 & Public & BA \\
Zhengping & Senior High-2 & 38 & F & 15 & Public(vocational) & BA \\
Yangke & Senior High-3 & 38 & F & 15 & Public & BA \\
Liangqing & Senior High-2 & 37 & F & 13 & Public & BA \\
Yeli & Senior High-1,2 & 30 & F & 3 & Public & BA \\
Hongying & university-1,3 & 39 & F & 5 & Public & MA(Russia) \\
Peisheng & university-1 & 65 & M & $38 / 5^{3}$ & Public/Private & BA \\
Shuqiong & university-2 & 37 & F & 15 & Public & PhD \\
Wangshu & university-2 & 35 & F & 7 & Public & PhD \\
Qingxin & university-2 & 35 & F & 6 & Public & MA(UK) \\
Xiaohong & university-1 & 40 & F & 17 & Public & BA \\
Jiean & university-1,2 & 35 & F & 13 & Public & MA \\
Luyi & university & 35 & F & 1 & Private & BA \\
\hline & & & & & & \\
\hline
\end{tabular}

\section{B. Instruments}

The main method used in eliciting data was the in-depth interview. The interviews were conducted either through faceto-face communication or by telephone. The language used in the interviews was Standard Chinese (Putonghua) or the local dialect spoken in the city where the field work was carried out. The time length ranged from 30 minutes to an hour or so, with one participant being interviewed twice.

\section{Data Analysis}

In the spirit of analytic induction (Bogdan \& Biklen, 1992), I repeatedly read through the interview transcripts during and after the field work in order to identify recurrent themes and salient comments. I started from the categories that arose from the group of questions set out in the interview guide. However, as the interaction between the interviewer and the interviewee developed, new themes or sub-categories manifested themselves, hence the emergence of a large set of possible categories. Judged on their relevance to the research questions and the recurrent frequency, four main categories were finalised and became the framework for the 'findings' section of this paper.

\section{FINDINGS}

This section is organised according to significant themes which were either informed by the interview questions or emerged from the analysis of the data. In the citations I make of the interview data, the coding begins with the participant's name. The pseudonym is followed by the educational level s/he was in (JH for Junior High, SH for Senior High and $\mathrm{U}$ for university).

\section{Overall attitudes toward the practice of text memorization:}

Overall, the overwhelming majority of participants thought positively of the practice of text memorization and acknowledged its benefit for language learning. Their attitudes in this regard differ only in terms of degree of endorsement, ranging from 'extremely useful' (Wenna, $\mathrm{JH}$ ) to 'at least not detrimental' (Yaoqing, JH). They perceived the practice to be effective in their language teaching:

From my teaching experience, doing textual memorization and not doing it may lead to drastically different outcome. (Qinxin, U)

The excellent students are usually those who are fond of reading aloud and memorising [texts]. (Wenna, $\mathrm{JH}$ )

The benefits of textual memorization is, to quote one of them, 'out of question' (Liangqing, $\mathrm{SH}$ ) so that many of them (16 out of 20) said that they would suggest to their students to memorise as many texts as possible 'if it does not pose a psychological burden' (Liuxia, JH).

Another interesting point I noticed is that almost all participants in their twenties were those who passionately or unreservedly recommended the practice of text memorization. 'Input' theory seems to be fairly typical of what they had to say to defend their belief: 
For people learning English in China, how can they improve without memorising a certain amount of language materials? Without input, how can you produce output? (Luyi, $U)$

It seems that the teacher participants' attitude toward the use of text memorization in language teaching was generally positive although some of them did not perceive themselves as being personal beneficiaries of the practice as English language learners.

\section{A. Attitudes Towards the Impact of Text Memorization on Understanding}

The relationship between memorising and understanding was addressed in the attempt to solve the paradox of Chinese learners, which is, Chinese learners achieve their equally often reported academic success apparently by using rote strategies and surface learning approaches. On the one hand, they are held up as paragons of educational excellence, while on the other hand, they are derided as rote learners (Biggs, 1991). One key aspect of solving the paradox is that Chinese learners tend to memorise what is understood and understand through memorization (Marton, Dall'Alba, \& Tse, 1996) rather than memorising mechanically without understanding. This was verified by the data from interviews with Chinese teachers of English conducted in this research:

It is out of question that you have to understand before you memorise [in any subject]. It is the same in foreign language learning - you need to understand [the text] before you are able to memorise it. (Peishen, $U$ )

At the same time, to memorise is considered to be facilitating understanding as 'the process of memorization is that of understanding' (Peishen, U). As a result, 'when s/he [the student] rereads the text s/he has memorised before, s/he certainly has a deeper understanding of it than if s/he has not'. (Liangying, $\mathrm{JH}$ )

Interestingly, many teachers even believe that the level of understanding can be, to some extent, judged by how well the student performs the recitation:

If one can recite well and pause appropriately between and in sentences, he/she must have understood the text. A tiny number of students do pause inappropriately in the process of recitation. It's apparently rote-memorization. (Liangqing, JH)

The underlying reasoning can be seen in the following account by another participant:

We often have long sentences in the texts in senior high school. They [the students] come across attributive clauses or something everywhere. Only when s/he understands [the grammar] and learns how to pause correctly in sentence, can $\mathrm{s} /$ he recite smoothly. (Yangke, $\mathrm{SH}$ )

\section{B. Attitudes Towards the Impact of Text Memorization on Creativity}

One prominent issue related to text memorization is creativity. When asked whether the practice of text memorization may limit the students' creativity, some participants seemed to be even puzzled by the question being asked:

I don't think there exists the issue of creativity [in foreign language learning]. (Liangqing, JH).

It doesn't relate much to creativity. (Peisheng, $U$ )

This is because language learning is thought to be more about imitation than creativity, at least in the early stage:

Imitation must be applied before creativity can be achieved. (Liangying, $U$ )

I consider the great importance attached to imitation in language learning and the awareness of the specificity of language learning as being one of the foundations for much of what participants said about the positive impact of text memorization on creativity. A participant put the relationship of memorization and creativity figuratively:

Without initial imitation and memorisation, creativity is like a stream losing its source. (Yuli, JH)

She insisted on the facilitative role of memorisation in the development of students' creativity:

The more one memorises, the wider horizon s/he has available to him/her. Having a great store of materials in one's mind, as I see it, can only help develop his/her creative thinking rather than restraining it. (Yuli, JH)

A similar idea was shared by most of the participants, one of whom used an analogy: 'How should one be able to walk without having learned to how to crawl?' (Xiaohong, $U$ )

These comments perhaps represent the typical Chinese attitude to learning and teaching: 'Learners must at least master the basics and only when this is accomplished are they in a position to use what they have mastered in a creative manner' (Brick, 1991: 154).

\section{Attitudes Towards the Impact of Text Memorization on Motivation}

An important issue which was explored in interview is the impact of the memorization of text on learners' motivation. I were aware that memorization is a process at which different people have different degrees of ability and toward which people's attitude may vary tremendously (Stevick, 1982). I was especially concerned about learners in secondary schools where text memorization, if any, is usually mandatory rather than optional. When I asked whether the practice could dampen down their interest in learning, many teachers' response was an unequivocal 'No'. One participant rejected the idea that there is a direct causal relationship between a certain way of learning a foreign language and the learners' interest, especially for adult learners:

From my [teaching] experience, most of those students who lose interest in learning a [foreign] language fit in the case that they feel they have not made good progress after learning for a while. ... It is not that a particular means of learning makes them lose interest. It is [that they fail to see] short-term outcomes. (Jiean, U) 
Interestingly, text memorization was seen as a means which may help the students easily see the product they produced, therefore stimulating their interest in learning:

Instead of killing their interest, the practice probably raises their interest. If they find that they can speak out some sentences fluently or write some good expressions in their composition, they will have a sense of achievement. From this point of view, the practice makes them more motivated in learning. (Liangqing, $\mathrm{SH}$ )

Although I felt there is a point in much of what the teachers said, I was still left with an impression that the teachers were generally not very sensitive to the learners as the students' attitude towards the practice was shunned by avoiding talking about it directly, consciously or not. The implied attitude, as I interpret it, might be congruent with what is conveyed in a participant's remark:

It is similar to children playing musical instruments. They have to do a lot of mechanical exercises at the beginning. Take playing piano as an example, the kids have to do much practice on musical scale which is not fun and even boring. But can you skip this stage? (Tangming, $\mathrm{JH}$ )

What is alluded to in the analogy is that that interest is not the main reason for doing a certain practice. When it comes to text memorization, even if it is not to some learners' taste, it cannot be left out if the teacher has enough experience and confidence to assess the value of the practice to learners at a given stage.

\section{CONCLUSION}

The most striking point arising from this interview - based study is that the teachers' comments regarding the use of text memorization in foreign language seem to be 'over-positive'. While cultural influence was acknowledged as a tacit term, the perceived benefits of the using text memorization as a teaching device became a more pronounced explanation given by the teachers. All in all, the findings of the present study echoes those of previous research on the learners' conceptions of text memorisation (Ting, 2007; Yu, 2014).

The results produced by the study show that the teachers' use of text memorisation as a teaching device is largely shaped by a myriad of contextual influences, including adverse learning context and the exam-oriented educational reality. In the current Chinese examination system, tests have been used as gatekeepers to success more than assessors of success (Han, 1992) and the design of large-scale English exams is based on structuralism (Wu, 2001). Assuming that effective change is unlikely to be managed unless the exam system changes (Cortazzi \& Jin, 1996), and if conditions for testing communicative ability remains unimproved, western-imported methodologies such as CLT may be doomed to failure in China. I would like to suggest that teachers use this teaching tool sparingly, sensitively and appropriately with clear objectives, because it can be a beneficial or valuable activity only when there is an element of choice or autonomy in doing it (Warner \& Crolla, 2015).

\section{REFERENCES}

[1] Biggs, J. (1991). Approaches to learning in secondary and tertiary students in Hong Kong: Some comparative studies. Educational Research Journal, 6, 27-39.

[2] Bogdan, R., \& Biklen, S. K. (1992). Qualitative research for education: An introduction to theory and methods London: Allyn \& Bacon.

[3] Brick, J. (1991). China: A Handbook in International Communication. Sydney: Macquarie University.

[4] Cortazzi, M., \& Jin, L.-X. (1996). Cultures of learning: language classrooms in China. In H. Coleman (Ed.), Society and the Language Classroom (pp. 169-206). Cambridge: Cambridge University Press.

[5] Gao, X.-S. (2007). From the Chinese mainland to Hongkong: understanding shifts in mainland and Chinese students' English learning strategy use. Unpublished $\mathrm{PhD}$ thesis, University of Hongkong, Hongkong.

[6] Han, J. (1992). Generativism and Behaviourism reconciled: A perspective into EFL teaching in China. Cross Currents, 19(2), 175-181.

[7] Huang, Q., \& Qi, Q. (Eds.). (2005). Speaking for Success. Shanghai: Shanghai Foreign Language Education Press.

[8] Jin, L.-X., \& Cortazzi, M. (2002). English language teaching in China: A bridge to the future. Asian-Pacific Journal of Education, 22(2), 53-64.

[9] Li, Y.-H., Zhang, P.-R., \& Wang, H.-X. (Eds.). (2001). College EnglishIntegrated Course, Book 1-4. Shanghai: Shanghai Foreign Language Education Press.

[10] Marton, F., Dall'Alba, G., \& Tse, L. k. (1996). Memorising and understanding: the key to paradox. In D. A. Watkins \& J. B. Biggs (Eds.), The Chinese learner: Cultural, Psychological and Contextual Influences (pp. 69-83). Hong Kong: University of Hongkong, Comparative Education Research Centre and Melbourne: Australian Council for Educational Research.

[11] Stevick, E. W. (1982). Teaching and Learning Languages. Cambridge: Cambridge University Press.

[12] Ting, Y. (2004). Learning English Text by Heart in a Chinese University. Xi'an: Shanxi Normal University Press.

[13] Ting, Y. (2007). Text memorization and imitation: The practices of successful Chinese learners of English. System, 35(1), 271-280.

[14] Warner, L., \& Crolla, C. (2015). The practice of reading aloud in the high school: a preliminary investigation. English Teaching: Practice \& Critique, 14(3), 419-426.

[15] Wen, Q.-F. (1996). English Learning Strategies. Shanghai: Shanghai Foreign Language Education Press.

[16] Wu, Y.-A. (2001). English language teaching in China: Trends and challenges. TESOL Quarterly, 35(1), 191-194.

[17] Yu, X. (2014). The use of textual memorisation in foreign language learning: Hearing the Chinese learner and teacher vocie. TESOL Journal, 22(4), 654-677. 